\title{
A 2006 Colima rift earthquakes series and its relationship to the Rivera-Cocos plate boundary
}

\author{
Jaime Yamamoto, Zenón Jiménez \\ Instituto de Geofisica, Universidad Nacional Autónoma de México, México, D.F.
}

Email address:

yamas@ollin.geofisica.unam.mx (J. Yamamoto)

To cite this article:

Jaime Yamamoto, Zenón Jiménez. A 2006 Colima Rift Earthquakes Series and Its Relationship to the Rivera-Cocos Plate Boundary. Earth Sciences. Vol. 4, No. 1, 2015, pp. 21-30. doi: 10.11648/j.earth.20150401.12

\begin{abstract}
From 31 July through 13 August 2006 a series of fourteen earthquakes (M 3.9 to 6.1) occurred in the western end of the Central Mexican Volcanic Belt (CMVB) in a twenty-five days period. The most prominent earthquake (Mw 6.1) occurred on 11 August 2006 at 14:30 UTC (9:30 local time) approximately at $18.37^{\circ} \mathrm{N}, 101.25^{\circ} \mathrm{W}$ and $81 \mathrm{~km}$ depth. The epicenter was less than $40 \mathrm{~km}$ from Huetamo, Michoacan a 41,250-inhabitant city and $60 \mathrm{~km}$ from the El Infiernillo dam embayment the third largest hydroelectric plant in Mexico. This earthquake was widely felt with minor to moderate reported damage. In Mexico City $250 \mathrm{~km}$ away from the epicenter the earthquake produced alarm among the population and several buildings were evacuated. The earthquakes series developed into two activity clusters one centered in the coast and separated about $300 \mathrm{~km}$ from a second inland cluster. The initial coastal cluster consisted of a nearly linear activity distribution, which includes shallow-depth earthquakes of reverse and normal faulting mechanisms. The inland cluster shows more compact and deeper hypocenters distribution. Earthquakes first-motion polarities indicate that ruptures occurred as a normal faulting, which is a characteristic of the CMVB earthquakes. The overall trend of earthquakes distribution shows two branches, one, along the El Gordo-Colima graben system direction $\left(\sim \mathrm{N} 45^{\circ} \mathrm{E}\right)$ nearly perpendicular to the coast and another along an east-west direction parallel to the southern border of the CMVB. Our results indicate that these two branches might constitute part of the continental extension of the Rivera-Cocos plate boundary.
\end{abstract}

Keywords: Seismicity, Colima Rift, Rivera Plate, Earthquake Triggering

\section{Introduction}

The central western is one of the most complex geotectonic regions of Mexico (Figure 1). Here, converge several geological units whose interactions give rise to a very complex seismic pattern. This region has been the site of numerous major earthquakes, including the largest magnitude earthquake (M 8.2) ever recorded in Mexico.

The 2006 series of earthquakes started with an inland isolated 4.2 magnitude earthquake on 17 July. The activity increased on 31 July in the coast of Colima, Mexico with the occurrence of four shallow-depth offshore earthquakes within a six days lapse. These first four events are located in recognized marine geological structure known as El Gordo graben, which seems to be an offshore extension of the Colima graben. After that, a magnitude 4.0 earthquake occurred inland $45 \mathrm{~km}$ from the coast inside the Colima graben. Eleven days after its beginning, the seismic activity migrated $300 \mathrm{~km}$ toward the east near the El Infiernillo hydroelectric plant with the occurrence of the strongest magnitude ( $\mathrm{Mw}$ 6.1) earthquake of the series at $81 \mathrm{~km}$ depth. Four more earthquakes of similar depth $(\sim 70 \mathrm{~km})$ followed. The activity returned to the coast of Colima with a shallow-depth normal faulting earthquake after seventeen days and progressively decayed until its disappearance. It is worthwhile to mention that the seismic activity associated to the coastal cluster decayed faster as compared to the inland cluster.

The interaction between the two plates, Rivera and Cocos, acting in the region is in a great extent the responsible of the observed seismic activity complexities. The precise location of the boundary between the Rivera and Cocos plates is still subject to debate because of the lack of a clear bathymetric feature associated to it [13]. Bandy [1] has suggested that the El Gordo graben located off the coast of Colima may be part of the plates boundary (see also [3]). Additionally, Suarez et al. [16] have proposed, based on the analysis of the 11 December 
1995 earthquake, that the marine portion of the Rivera-Cocos boundary is an east-west oriented zone of right-lateral faults. The 2006 earthquakes fault plane solutions and the epicenters distribution show two clear activity tendencies, one along the rift suggesting that its origin may be related to the Rivera-Cocos plate boundary. Therefore, the analysis of the 2006 earthquakes series provides the opportunity to understand the plates boundary structure and its dynamic behavior.

The space and time clustering of the 2006 earthquakes series suggests a causal relationship among their members. In such a way that the coastal shallow seismic activity could somehow trigger the deeper inland activity. However, establishing a causal association between them is not straightforward due to its $300 \mathrm{~km}$ separation. Since theoretically has been proven that at this range of distance the influence should be considered negligible. There are however, numerous reports of long distance interaction particularly after the 1982 Landers earthquake [8]. The long distance earthquakes triggering issue is important for establishing our conclusions and the proper assignation the seismic risk potential of a region and its study should be considered of primary importance.

Thus, the present paper has several purposes first, to study the main seismic characteristics of the earthquakes series and its interpretation in terms of the geotectonic knowledge of the region second, to discuss if the two seismic clusters shown by the earthquakes responds to a long distance triggering effect or they are just two independent phenomena. And finally, to explore the possibility that the spatial distribution of the 2006 earthquakes epicenters delineates the Rivera-Cocos plate boundary.

\section{Geotectonic Setting}

In central western Mexico several geologic units interact in a very complex manner originating an intricate seismic occurrence pattern (Figure1). Due to its importance, many geophysical studies (see [1], [3], [17]) have been carried out in this region and the overall geotectonic behavior is fairly well understood. However, details of the seismic characteristics of the region and its connection to recognized geological features still obscure and additional effort is required.

South of the Gulf of California and separated by the Tamayo Fracture Zone the Rivera plate subducts under the North America plate along the northern portion of the Middle America Trench (MAT) at a low convergence rate of approximately $2.5 \mathrm{~cm} /$ year [4]. The Rivera Fracture Zone on the other hand, is considered the marine contact portion between the southern border of the Rivera plate and the Cocos plate, which in turn, subducts obliquely under de North America plate at a higher convergence rate of $5.2 \mathrm{~cm} /$ year [5]. The limits and the characteristics of the interaction motion between both plates are not well understood nor established. Due to these differences in subduction rates and convergence direction of the plates, Rivera and Cocos, a complex seismic generation pattern arises. Data indicates that both plates subduct under the North America plate with an initial angle of approximately $10^{\circ}$ and gradually increasing the subduction angle up to approximately $50^{\circ}$ ([12], [17]).

The regional geological structure of the continental portion is also very complex but seems formed by three cortical blocks, Jalisco, Michoacan and Guerrero, separated by graben structures and fault zones. The presence of the western portion of the CMVB introduces additional structural complexity in the region. The continuous volcanic activity shown by the Volcano of Colima is the best example of the intense tectonic activity of the region.

\section{Seismicity of the Region}

Central western of Mexico evolved as a consequence of the collision between the Rivera plate at north, Cocos plate at south and the North America plate at east. The collision resulted in a significant amount of stress accumulation causing intense seismic and tectonic activity of the region. In the central western region, seismicity consists mostly from shallow to intermediate depth earthquakes. Generally, the seismic pattern shows a diffuse nature and seems not to follow clearly a particular tectonic trend. The focal mechanisms solutions here are predominantly of reverse at the coast and normal type inland, which are further attributed to the subduction process of the Cocos plate under the North America plate and the faulting characteristic of the CMVB respectively.

\subsection{Historical Seismicity}

Recorded evidence indicates the occurrence of several major earthquakes near the coast along the segment Jalisco-northern Guerrero, of particular importance is the series of major earthquakes occurred in June 1932 (7 $\leq \mathrm{M} \leq$ 8.2 ) in the region. Figure 1 shows the most relevant earthquakes of the region to our study. Most of these earthquakes are shallow-depth focus located between the coast and the MAT. Focal mechanisms solutions for these earthquakes are of reverse faulting type on a low-angle $\left(\sim 17^{\circ}\right)$ plane resulting of either the subduction of the Rivera or Cocos under the North America plate. In most cases, the association of earthquakes to a particular regional geological unit in this area is difficult due to the lack of well-defined separation boundaries. It has been accepted however, that the series of major earthquakes of Jalisco-Colima of 1932, the earthquake of 1995 and the Tecoman earthquake of 2003 occurred along the interplate of the Rivera and North America plates (see [15], [6], [11]). The remaining earthquakes shown in Figure 1 have been associated to the subduction of the Cocos plate under the North America plate. All the events are typical shallow-depth subduction earthquakes with preferred fault plane oriented NNW-SSE and dipping toward the NE as reported by several authors ([15], [6]).

\subsection{Ongoing Seismicity}

The Figure 1 displays also the overall seismic activity ( 3.0 
$\leq \mathrm{M} \leq 6.7$ ) in the zone of interest for 2000 to 2010 period with data published by the Seismological Service of Mexico and the Colima regional seismic network (RESCO). The Figure 1 shows clearly the great complexity of the seismic patterns of the region. Several seismic activity bands are apparent, the most active directed northwest-southeast following the trend of the coast and MAT, and a less active band east-west following the southern border of the CMVB. The area limited by the coast and the Lake of Chapala shows scarce seismic activity except at the Volcano of Colima zone in which the seismic activity is increased.

\section{The 2006 Series of Earthquakes}

\subsection{Hypocentral locations}

In the Table 1 and Figure 2 we list the hypocenter parameters of the 2006 earthquake series as recalculated in this paper and plot their position. Arrival times of $\mathrm{P}$ and $\mathrm{S}$ waves recorded by the permanent seismic station network (short-period and broad-band) of the Seismological Service of Mexico and the Colima regional seismic network (RESCO) were used. RESCO velocity model (see Figure 3A) was used in the location procedure because is an average model among the various proposed for this region. The RESCO velocity model was developed in 1990 using mine explosions at the nearby Peña Colorada and Las Encinas mines and since then it has been refined through its use.

Five stations recorded the smallest magnitude earthquake and 17 the largest. The standard deviation (rms) of the location was in average $0.29 \mathrm{~s}$. All the computations were carried out with the SEISAN seismic analysis package [9]. The quality of the seismic signals arrival indicates that epicentral locations of the earthquakes are quite reliable since the error is in average $\pm 1.96 \mathrm{~km}$ along the horizontal direction (see Table 1). The calculated hypocenters depths on the other hand, are less precise but according to our analysis, in general, is in average $\pm 2.77 \mathrm{~km}$. To ensure a correct focal depth computation, graphs of standard deviations versus depth for each earthquake were calculated. The depths obtained by the Hypocenter program were then crosschecked with the minimum of the graphs (see Figure 3B) and in some cases with the sP-P interval (see Figure 3C).

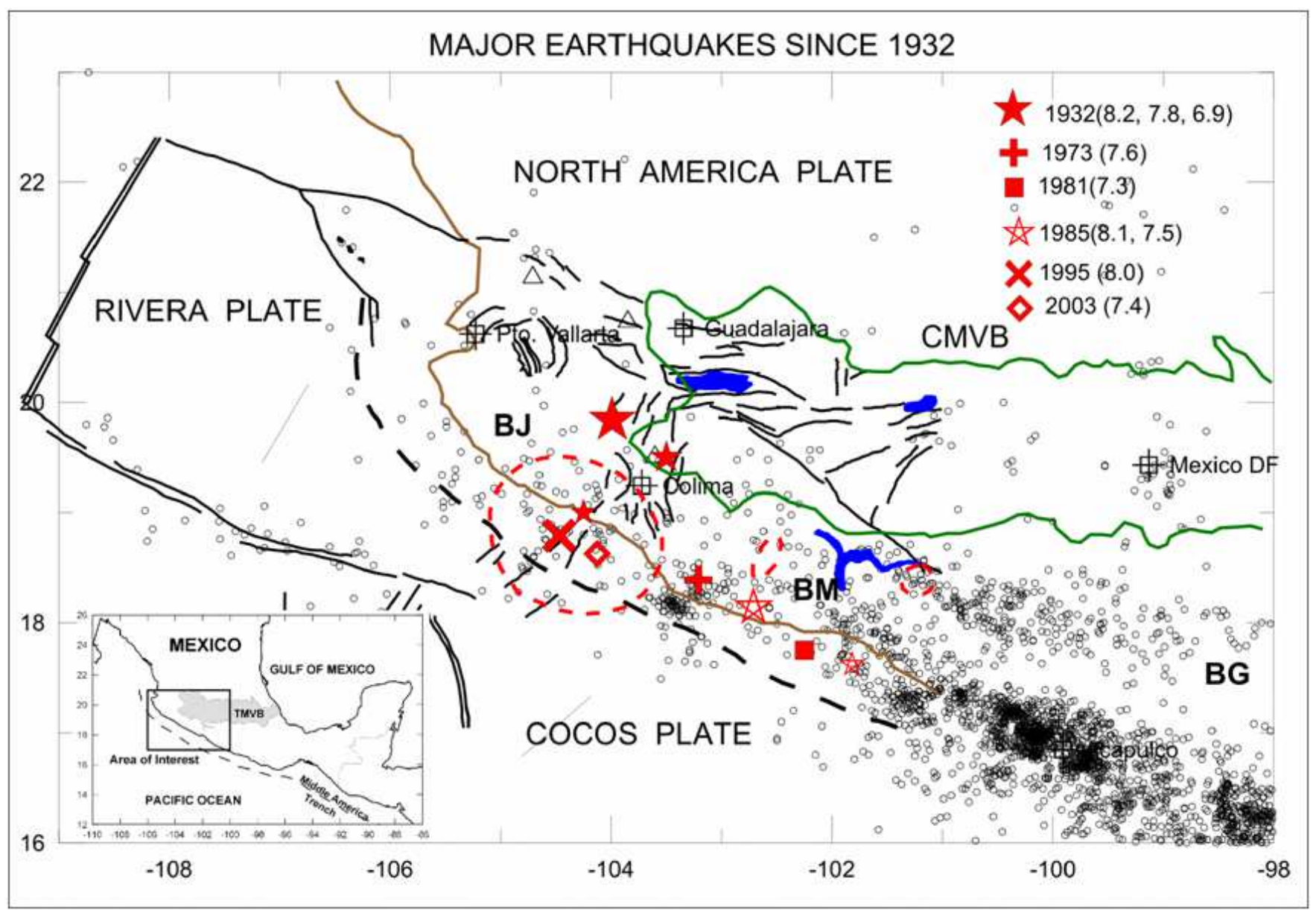

Figure 1. The region of interest is shown with the rectangle. Historic seismic map of central western Mexico. Epicenters of major earthquakes occurred in the area from 1932 are shown. The ongoing seismic activity from 2000 to 2010 is shown with open circles. Triangles are active volcanoes. Fault traces are shown with segments of lines. BJ, BM and BG are the Jalisco, Michoacan and Guerrero block respectively. CMVB is the approximate limit of the Central Mexico Volcanic Belt. The 2006 seismic series is shown with dashed line. (Insert): Location map. Gray-shaded region corresponds to the Central Mexico Volcanic Belt. MAT is the Middle America trench. 
Table 1. 2006 earthquakes series. Location errors as computed by the SEISAN analysis program are listed.

\begin{tabular}{|c|c|c|c|c|c|c|c|c|c|c|c|c|c|c|c|}
\hline Num & Year & Mon & Day & Origin time & Lon (W) & Lat(N) & Depth & MD & M NEIC & Type/Autor & Rms & Erh & Erz & Erx & Oterr \\
\hline 1 & 2006 & 7 & 17 & $19: 46: 21.46$ & -102.6745 & 18.4243 & 28.8 & 4.3 & 4.2 & MDUNM & 0.3 & 2.2 & 5.5 & 1.3 & 0.55 \\
\hline 2 & 2006 & 7 & 31 & $17: 54: 45.81$ & -104.5017 & 18.1470 & 16.1 & 4.6 & 4.4 & $\mathrm{mbGS}$ & 0.3 & 3.5 & 2.5 & 2.9 & 0.42 \\
\hline 3 & 2006 & 7 & 31 & $18: 25: 18.61$ & -104.0245 & 18.7497 & 13.2 & 4.9 & 5.3 & MwHRV & 0.27 & 1.7 & 2.3 & 1.2 & 0.45 \\
\hline 4 & 2006 & 8 & 1 & $05: 56: 10.48$ & -104.1507 & 18.5650 & 5.1 & 4.2 & & & 0.3 & 2.3 & 2 & 1.3 & 0.59 \\
\hline 5 & 2006 & 8 & 3 & 01:04:29.05 & -104.8280 & 18.2865 & 12.1 & 3.5 & 4.3 & $\mathrm{mbGS}$ & 0.29 & 2.2 & 2.1 & 1.3 & 0.43 \\
\hline 6 & 2006 & 8 & 5 & $00: 43: 54.70$ & -103.8393 & 19.2383 & 16.7 & 3.5 & 4 & MDUNM & 0.27 & 1.2 & 1.6 & 0.9 & 0.48 \\
\hline 7 & 2006 & 8 & 11 & $14: 30: 39.45$ & -101.2492 & 18.3677 & 81.3 & 5.5 & 6.1 & MwHRV & 0.33 & 1.6 & 3.5 & 0.9 & 0.64 \\
\hline 8 & 2006 & 8 & 11 & $14: 38: 36.09$ & -101.2698 & 18.4208 & 72.9 & 4.8 & 5.4 & $\mathrm{mbGS}$ & 0.45 & 1.7 & 4.8 & 1 & 0.61 \\
\hline 9 & 2006 & 8 & 11 & $16: 46: 24.43$ & -101.2812 & 18.4108 & 68.6 & 4.6 & 4.9 & $\mathrm{mbGS}$ & 0.31 & 0.9 & 2.8 & 0.5 & 0.34 \\
\hline 10 & 2006 & 8 & 13 & $15: 14: 24.46$ & -103.6580 & 18.3313 & 17.7 & 5.1 & 5.3 & MwHRV & 0.25 & 1.6 & 1.1 & 0.7 & 0.31 \\
\hline 11 & 2006 & 8 & 17 & $23: 34: 51.29$ & -102.5092 & 18.7207 & 74.3 & 4.6 & 4.6 & MDUNM & 0.21 & 1.1 & 3.1 & 0.7 & 0.30 \\
\hline 12 & 2006 & 8 & 19 & $16: 33: 57.20$ & -103.6427 & 18.3637 & 12.1 & 4.3 & 4.2 & MDUNM & 0.24 & 1.9 & 1.8 & 1.3 & 0.33 \\
\hline 13 & 2006 & 8 & 20 & $15: 49: 04.07$ & -101.1553 & 18.3797 & 71.5 & 3.5 & 3.9 & MDUNM & 0.15 & 1.1 & 3 & 0.6 & 0.29 \\
\hline 14 & 2006 & 8 & 25 & $08: 42: 39.04$ & -105.0730 & 19.0333 & 15 & 4.3 & 4.3 & MDUNM & 0.35 & 3.9 & 3.5 & 2.6 & 0.85 \\
\hline 15 & 2006 & 8 & 26 & $21: 33: 5.83$ & -104.8805 & 19.3460 & 16.1 & 4.5 & 4.3 & MDUNM & 0.34 & 2.5 & 2 & 1.3 & 0.59 \\
\hline
\end{tabular}

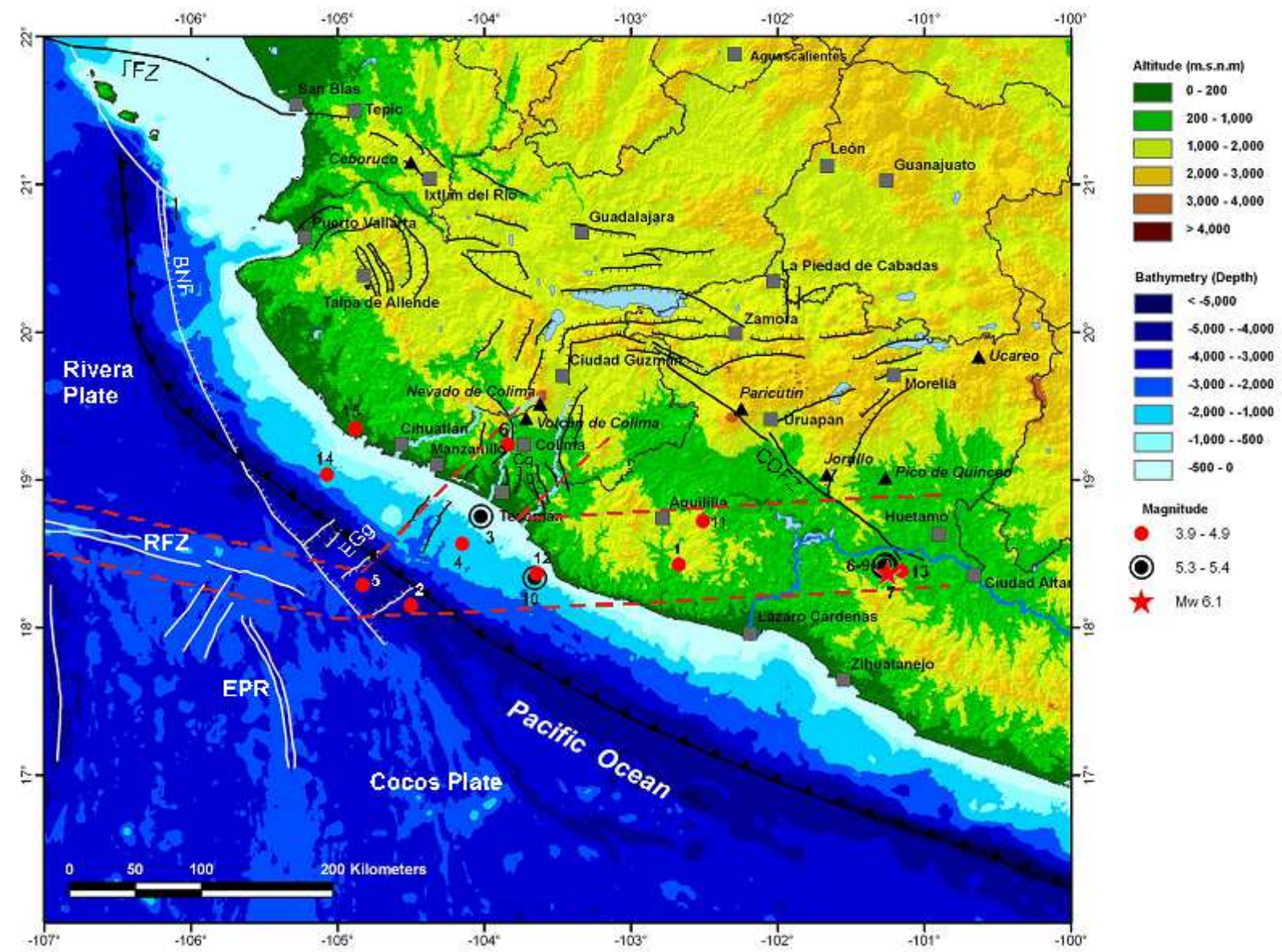

Figure 2. The 2006 earthquakes series epicenters map. The location of the earthquakes analyzed is listed in Table 1. TFZ and RFZ are the Tamayo and Rivera fracture zones respectively. BNF and COFZ are the Barra de Navidad and Chapala-Oaxaca fault zones respectively. EGg and Cg denote El Gordo and Colima graben respectively. Spiked lines are recognized normal faults. Dashed lines mark the observed 2006 activity trends.

The entire 2006 earthquakes series clusters in two well defined seismic activity zones, one near the coast and other inland separated $300 \mathrm{~km}$ to the east. The foci depths of the events in the two clusters are also different. The initial stage of the costal cluster presents a linear distribution of shallow-depth focus earthquakes $165 \mathrm{~km}$ long oriented nearly perpendicular to the trench (see Event 2 through 6 of Table 1) located along the El Gordo-Colima graben system. Most of the earthquakes lie between the trench and the coast. Oppositely, in the inland cluster the distribution of earthquakes is more compact and the foci depths deeper. At its final stage the seismic activity distribution of epicenters follows an east-west direction. The first earthquakes cluster occurs at the supposed boundary between the oceanic Rivera plate and Cocos plates. It must be emphasized that the entire spatial distribution of earthquakes delineate two branches of activity, one in the direction of the El Gordo-Colima graben system nearly perpendicular to the MAT and coast and other oriented 
east-west of about $340 \mathrm{~km}$ long.

\subsection{Fault Plane Solutions and their Interpretation}

Fault plane solutions of eight events (Event 3 to 10 of Table 1) of the earthquakes series were obtained using the regional distribution of P-wave polarities as recorded by short-period and broadband stations. In general, the polarities recorded are reasonable clear and can be interpreted without ambiguity, particularly the intermediate-depth earthquakes. The fault mechanism solutions parameters and the polarities distribution diagrams are shown in the Table 2 and Figure 4.
The major source of uncertainty is due to the lack of data, in some cases, at certain critical observation points. However, even with those limitations the solutions are considered reliable for most earthquakes analyzed.

It should be mentioned that for Events 3, 7 and 10 additional CMT inversion solutions are available (see CMT global catalog and Figure 4). Although both solutions (CMT and first arrival polarities) are similar, we prefer the polarity method results since CMT solutions lead to several polarity inconsistencies at some stations.
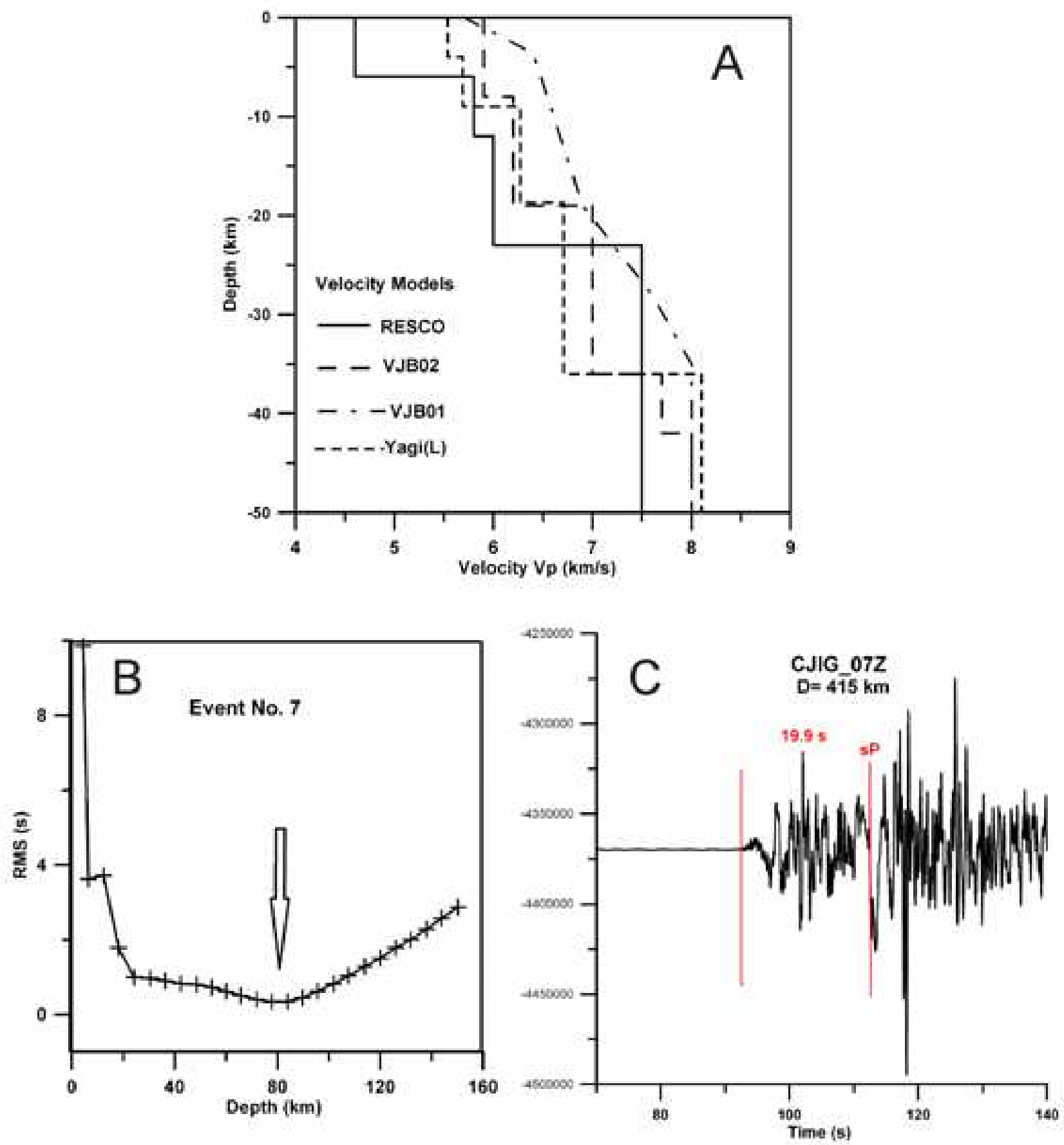

Figure 3. (A) Proposed velocity models (P-wave) for the region as published by several authors (see [14], [11]). (B) Hypocentral location RMS vs. Depth plot for the largest magnitude event. (C) Example of $s P$ wave interpretation for Event 7. 
Table 2. Fault plane solutions for some of the earthquakes listed in Table 1.

\begin{tabular}{llllllllllll}
\hline Num & Az_A & Dip_A & Rake_A & Az_B & Dip_B & Rake_B & Az_P & Dip_P & Az_T & Dip_T & Type \\
\hline 3 & 280 & 42 & 65.1 & 132 & 52.6 & 110.8 & 207.4 & 5.5 & 99.3 & 72.7 & Reverse \\
4 & 265 & 50 & 32.2 & 153 & 65.9 & 135.3 & 212.4 & 9.6 & 111.6 & 48 & Reverse \\
5 & 338 & 50 & -104.6 & 180 & 42.1 & -73.3 & 187.8 & 78.2 & 78.3 & 4 & Normal \\
6 & 339 & 46.1 & -78.8 & 143 & 45 & -101.5 & 327.1 & 81.9 & 61.1 & 0.6 & Normal \\
7 & 296 & 44.7 & -99.3 & 129 & 46 & -80.9 & 117.1 & 83.4 & 212.6 & 0.6 & Normal \\
8 & 290 & 40 & -101.6 & 125 & 51 & -80.4 & 81.8 & 80.7 & 208.2 & 5.5 & Normal \\
9 & 289 & 35 & -97.4 & 118 & 55.3 & -84.9 & 47.3 & 78.5 & 204.3 & 10.2 & Normal \\
10 & 339 & 60 & -106.1 & 189 & 33.7 & -64.3 & 213.3 & 70.4 & 80.6 & 13.6 & Normal \\
\hline
\end{tabular}
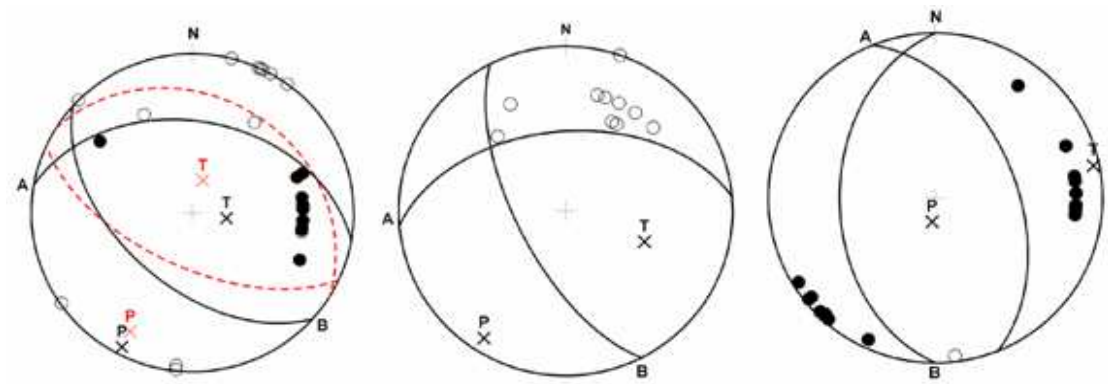

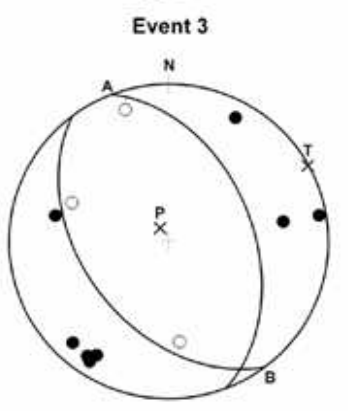

Event 6

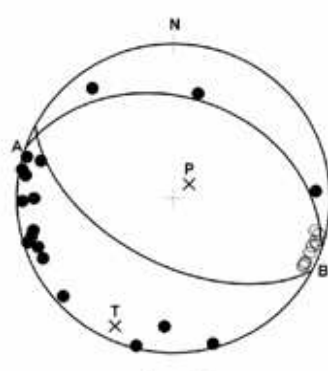

Event 9

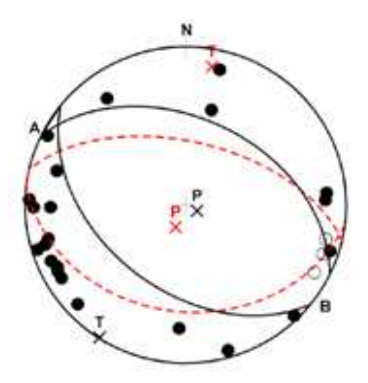

Event 7
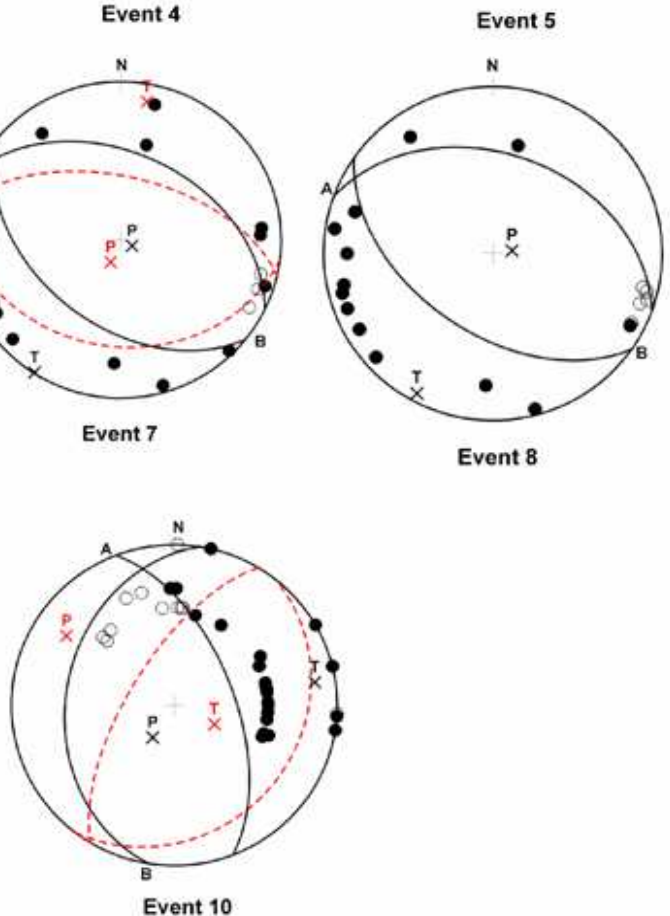

Figure 4. First arrival polarities distributions and the corresponding of fault plane solutions of the events listed in Table 2. Filled and open circles are compression and dilatation P-wave polarities respectively. CMT inversion solution when available are shown with red dashed lines [7].

The interpretation of the accepted fault plane solutions in terms of the tectonic setting is as follows:

Event 3 and 4: These two interplate events occur between the trench and the coast at very shallow depth $(\sim 13$ and $5 \mathrm{~km})$. Even though these events are located near the El Gordo-Colima graben system, their origin is probably related to the plates subduction process. Their fault plane solutions indicate reverse faulting typical of subduction earthquakes with and slight strike-slip component. The nodal planes of the two earthquake solutions (see Figure 4), the plane A with azimuth $280^{\circ}$ and $265^{\circ}$ and dipping $42^{\circ}$ and $50^{\circ}$ respectively toward the $\mathrm{N}$ are congruent with the angle of subduction of either the Rivera or Cocos plate under the North America plate in this region. If this plane is assumed to be the rupture plane, the strike-slip component resulted to be left lateral. Considering the geographical position of the earthquakes epicenters, their origin is likely related to the relative motion, generated by the different convergence rates, along the boundary between Rivera and Cocos plates. The azimuth of plane A is reasonably well constrained and the dip obtained is probably a good estimation of the real inclination of the oceanic plate in this area [10]. Thus, plane A seems to be consistent with the relative motion of the plates, which requires a left lateral motion at the boundary of the plates, Rivera and Cocos. Interpretation of the fault plane solutions is difficult because earthquakes occur along the boundary of the 
two plates. Since the Rivera plate shows a rotation with respect of the Cocos plate it is probably a plate overlap at depth complicating the interpretation. It should be note that for Event 4 there are several possible focal mechanism solutions. The chosen one is because its distribution of polarities is similar to the Event 3.

Event 5: This event is also a shallow depth earthquake $(\sim 12$ $\mathrm{km}$ ) occurring inside the El Gordo graben along the same line of the previous events but west of the trench. It shows a normal fault solution with two possible fault planes oriented nearly NS. Assuming that the plane A, dipping approximately $50^{\circ}$ toward the northeast corresponds to the fault plane (see Figure 4), the displacement along the fault plane will be congruent with the expect motion in a graben zone. It should be noted that the focal mechanism for this earthquake admits several solutions and both nodal planes are not well constrained.

Event 6: This normal fault earthquake occurs inland $43 \mathrm{~km}$ from the coast slightly deeper $(\sim 17 \mathrm{~km})$ than the previous offshore events. It is located in the Colima graben and the strike of any of the two nodal planes (NNW) is transversal to the direction of the graben $\left(\sim \mathrm{N} 45^{\circ} \mathrm{E}\right)$ but the slip motion is the expected in this type of structure. The nodal plane A dipping $46^{\circ}$ toward the NE is preferred as fault plane. Both nodal planes are reasonably well constraint.

Event 7, 8 and 9: These three events occurred about $300 \mathrm{~km}$ inland east of the costal cluster at the vicinity of the El Infiernillo hydroelectric plant and the city of Huetamo, Michoacan. They show deeper focal depths ( 81, 73 and 69 $\mathrm{km})$. This cluster includes the strongest ( $\mathrm{Mw} 6.1)$ event of the series. All the events show normal faulting characteristic of the intermediate depth earthquakes of the central Mexico. The possible fault planes are reasonably well constrained and oriented NWW-SEE similar to the trend of the Chapala-Oaxaca fault zone (COF) geological feature observed at surface. In spite of the limited accuracy, it is clear that the nodal planes strikes of these earthquakes are more westerly than the costal cluster normal earthquakes. The south boundary of the CMVB runs approximately east west in this area.

Event 10: This event located at the edge of the costal cluster offshore the Colima graben occurred at the late state of the earthquakes series. It is a shallow-depth $(\sim 18 \mathrm{~km})$ earthquake with a normal fault mechanism and a probable fault plane oriented NNW-SSE nearly perpendicular to the trend of the graben system. Therefore, its occurrence could be related to a manifestation of the graben, rather to the subduction process.

Figure 5 shows the beach ball diagrams of the fault mechanisms solutions of all earthquakes analyzed and its association with known regional geological features.

Figure 6A is a cross section of the earthquakes shown in Figure 5 along the direction of the El Gordo-Colima graben system. The normal faulting earthquakes occurred in the extremes of the graben system are consistent with this type of structure and the reverse faulting earthquakes for its location and focal depth seems to be a response of the Rivera plate subduction under the North America plate. In the same figure, it has been plotted approximately the interplate boundary as published by Pardo and Suarez [13]. Figure 6B is a cross section along the E-W direction. Most of the activity occurred under the Chapala-Oaxaca fault zone. The limit between the Rivera and North America plates [13] are also plotted. It should be emphasized that the E-W distribution tendency does not follow the plate's convergence direction.

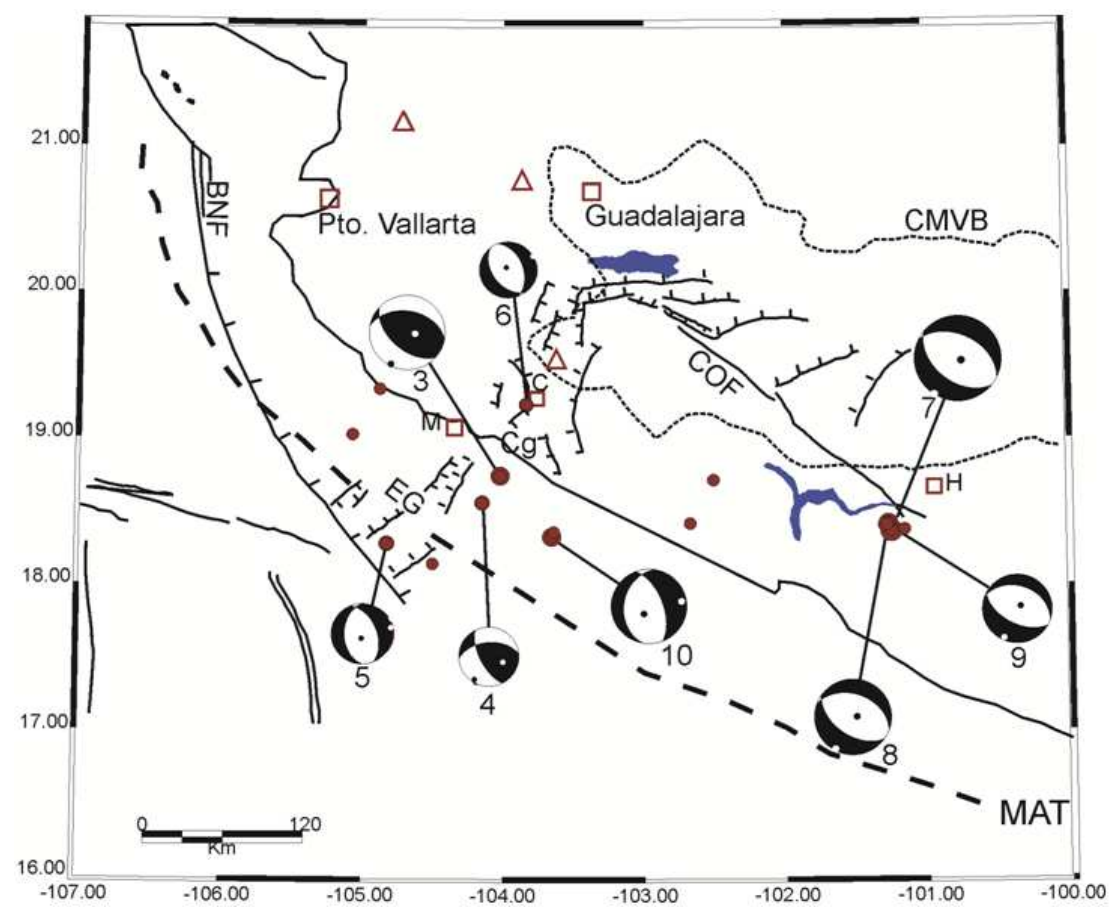

Figure 5. Map shows fault plane solutions (beach balls diagrams) of the earthquakes analized and their association with known geological features. Dark sections in diagrams are compression. Triangles are active volcanoes. Colima (C), Manzanillo (M) and Huetamo (H) cities are shown with squares. BNF and $C O F$ are Barra de Navidad and Chapala-Oaxaca fault zones respectively. EG and Cg are el Gordo and Colima graben respectively. 
a)

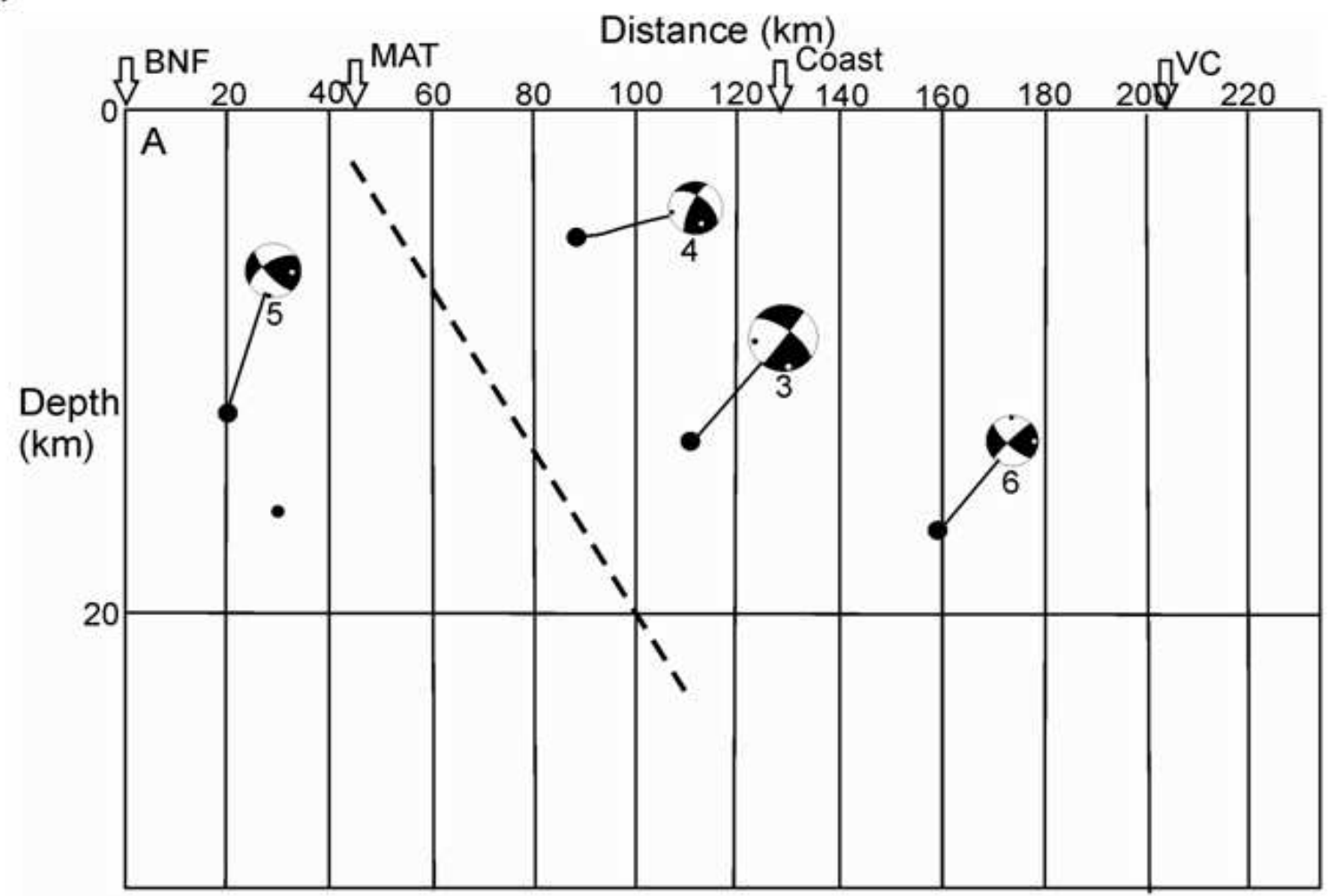

b)

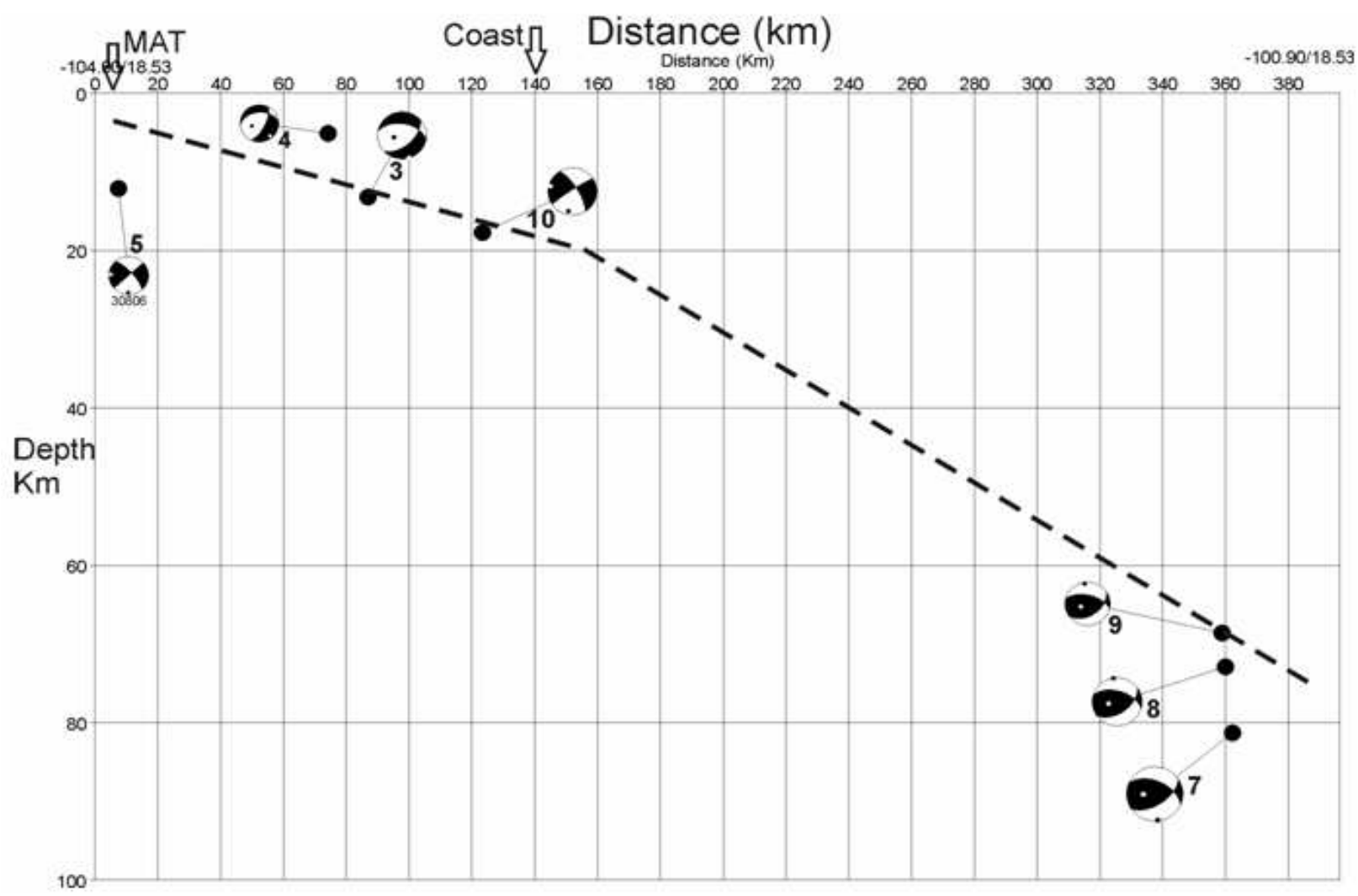

Figure 6. (A). Seismic activity profile along the El Gordo-Colima graben system $\left(\sim N 45^{\circ} \mathrm{E}\right)$ starting at $18.0 \mathrm{~N}, 104.8 \mathrm{~W}$. VC indicates the approximate position of the Colima Volcano (B) Profile along the E-W direction. Focal mechanisms diagrams have been projected on the profile plane. Dashed line represents the approximate boundary of the ocean and continental plates [13]. 


\section{State of Stress}

In Figure 7 has been plotted the preferred fault planes of the earthquakes and the T-axis directions. The orientations of the preferred fault planes of the normal faulting earthquakes are consistent with regional known normal faults, particularly the Barra de Navidad normal fault [3]. In general, the direction of the normal fault planes found are oriented NW-SE which is roughly the trend of the known faults in the region.

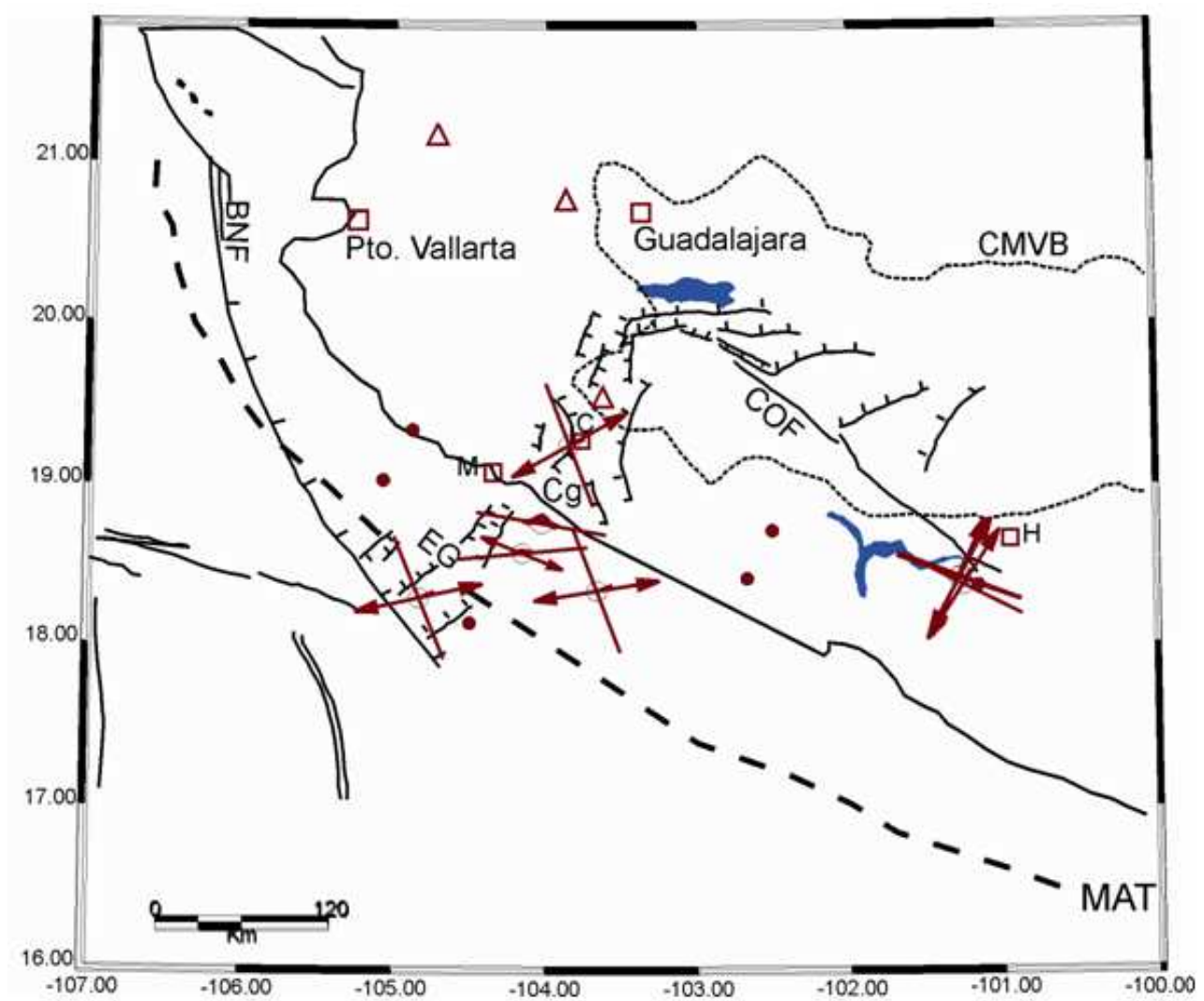

Figure 7. Preferred fault planes and the distribution of the T-axis. H and COF are the City of Huetamo and the Chapala-Oaxaca fault system respectively

Thus, our results indicate the existence of a wide band of tensional stresses and consequently a zone of crust extension along the southern border of the CMVB. Due to the limited amount of data, its precise dimension cannot be established. This result is consistent with previous results suggesting that this region is a distention region based on geological observations. In this context, Bandy et al. [2] based on a gravity profile carried out transversal to the Colima graben found a low density layer at $150 \mathrm{~km}$ depth. According to them, the anomaly oriented as the El Gordo-Colima graben system is related to the Rivera-Cocos plate boundary and corresponds to a zone of extension.

\section{Discussion and Conclusions}

The analysis of the 2006 earthquakes series shows two clear clusters of earthquakes one around the coast and other inland their characteristics can summarize as it follows:

1. The genesis of the earthquakes in the coastal clusters can be related to two different origins even though not necessarily independent phenomena. The initial earthquakes of the series are shallow-depth events located between the coast and MAT near the Rivera and Cocos plates boundary therefore, their occurrence probably is affected by this feature. Assuming the east west trending nodal plane as the fault plane the strike-slip component of the solution results to be left lateral. This left lateral motion is consistent with the requirements imposed by the relative motion between the Rivera and Cocos plate. The observed fault mechanisms of these two earthquakes are consistent with the subduction of the Rivera plate under the North America plate.

2. The first stage of the earthquakes series shows a near linear epicenter distribution located along the mapped structure El Gordo-Colima graben system. The normal fault events of the coastal cluster lie along the graben system therefore, their origin is probably related to the graben blocks motion. Naturally, the instability in the graben would be a consequence of the subduction process.

3. Intermediate-depth earthquakes and normal-faulting mechanism with the preferred rupture plane oriented northwest-southeast form the inland cluster. The epicenters distribution and the direction of the preferred 
fault plane are similar to the direction of the Chapala-Oaxaca fault system trace.

4. The final overall distribution of seismic activity of the 2006 earthquakes series shows two branches one, in the direction of the El Gordo-Colima graben system $\left(\mathrm{N} 45^{\circ} \mathrm{E}\right)$, which corresponds to the Rivera plate convergence direction, and other in the east-west direction following the southern edge of the CMVB. This result is important in establishing the position of the boundary between Rivera and Cocos plates. Thus, our results suggest that the two observed branches of seismicity associated with the 2006 earthquakes series could be associated to the continental extension of the Rivera-Cocos plate boundary. The prominence of the normal faulting among the 2006 series earthquakes indicates the existence of an extensional band in the area of occurrence.

5. Finally, the continuity of the seismic activity connecting the two observed earthquake clusters suggest a causal relationship between them, in such a way that thrust earthquakes in the coast may trigger normal faulting earthquakes inland.

\section{Acknowledgements}

Seismic data used in earthquakes relocation were supplied by the Seismological Service of Mexico and the Colima regional seismic network (RESCO). Collaboration of L. Godinez in preparing the figures is greatly appreciated. We thank to anonymous reviewer for his comments and suggestions.

\section{References}

[1] Bandy, W.L., 1992. Geological and geophysical investigation of the Rivera-Cocos plate boundary: Implications for plate fragmentation. Ph.D. dissertation. Texas A \& M Univ. College Station.

[2] Bandy, W., C. Mortera-Gutierrez, J. Urrutia-Fucugauchi, and T. W. Hilde, 1995. The subducted Rivera-Cocos plate boundary: Where is it, what is it, and what is its relationship to the Colima rift?. Geophys. Res. Letters, 22, 3075-3078.

[3] Bourgois, J. and F. Michaud, 1991. Active fragmentation of the North America plate at the Mexican triple junction area of Manzanillo. Geo-Marine Letters, 11, 59-65.

[4] DeMets, C., R. Gordon and S. Stein. 1994. Effect of recent revisions of the geomagnetic reversal time scale on estimates of current plate motions. Geophys. Res. Lett., 21, 2191-2194
[5] DeMets, C. and D.S. Wilson, 1997. Relative motions of the Pacific, Rivera, North American, and Cocos plates since 0.78 Ma. J. Geophys. Res., 102, 2789-2806.

[6] Eissler H. K., and K.C. McNally, 1984. Seismicity and tectonics of the Rivera plate and implications for the 1932 Jalisco, Mexico earthquake. J. Geophys. Res., 89, 4520-4530.

[7] Global Centroid Moment Tensor Project. (2014). http://www.globalcmt.org/CMTsearch.html

[8] Gomberg, J., and P. Bodin, 1994. Triggering of the Ms=5.4 Little Skull Mountain, Nevada earthquake with dynamic strain. Bull. Seism. Soc. Am., 84, 844-853.

[9] Havskov, J., and L..Ottemöller, 1999. Seisan earthquake analysis software. Seism. Res. Letters, 70, 532-534.

[10] Kim, Y., R.W. Clayton, and J.M. Jackson, 2010. Geometry and seismic properties of the subducting Cocos plate in central Mexico. J. Geophys. Res., 115, B06310, doi:10.1029/2009JB006942, 2010.

[11] Nuñez-Cornú, F. J., G. A. Reyes-Dávila, M. Rutz Lopez, E. Trejo Gómez, M. A. Camarena-García, and C. Ariel Ramirez-Vazquez. 2004. The 2003 Armería, México Earthquake (Mw 7.4): Mainshock and early Aftershocks. Seism. Res. Lett., 75, 734-743.

[12] Pardo, M. and G. Suarez. 1993. Steep sbduction geometry of the Rivera Plate beneath the Jalisco Block in western Mexico. Geophysical Research Letters, 20, 2391-2394.

[13] Pardo, M. and G. Suarez, 1995. Shape of the subducted Rivera and Cocos plates in southern Mexico: Seismic and tectonic implications. J. Geophys. Res., 100, 12357-73.

[14] Santoyo, M. A., T. Mikumo and L. Quintanar. 2006. Faulting process and coseismic stress change during the 30 January, 1973, Colima, México, eartquake $(\mathrm{Mw}=7.6)$. Geofisica Internacional, 45, 163-178.

[15] Singh, S.K., L. Ponce and S.P. Nishenko. 1985. The great Jalisco, Mexico earthquakes of 1932: Subduction of the Rivera plate. Bull. Seism. Soc. Am.. 75, 1301-1313.

[16] Suarez, G., D. Escobedo, W. Bandy, and F. Pacheco, 1999. The 11 December, 1995 earthquake $(\mathrm{Mw}=6.4)$ : Implications for the present-day relative motion on the Rivera-Cocos plate. Geophys. Res. Letters, 26, 1957-1960.

[17] Yang, T., S.P. Grand, D. Wilson, M. Guzman-Speziale, J.M. Gomez-Gonzalez, T. Dominguez-Reyes, and J. Ni. 2009. Seismic structure beneath the Rivera subduction zone from finite-frequency seismic tomography. J. Geophys. Res., 114, B01302, doi: 10,1029/2008JB005830. 